\title{
Epidemiological and etiological investigation of dengue fever in the Fujian province of China during 2004-2014
}

\author{
Jinzhang Wang ${ }^{1}$, Hongbing Chen ${ }^{1}$, Meng Huang ${ }^{1}$, Yongjun Zhang ${ }^{1}$, Jianfeng Xie ${ }^{1}$, \\ Yansheng Yan ${ }^{1,2}$, Kuicheng Zheng ${ }^{1,2}$ \& Yuwei Weng ${ }^{1,2^{*}}$ \\ ${ }^{1}$ Fujian Center for Disease Control and Prevention, Fuzhou 350001, China; \\ ${ }^{2}$ College of public health, Fujian Medicine University, Fuzhou 350001, China
}

Received March 23, 2016; accepted April 14, 2016; published online October 31, 2016

\begin{abstract}
Dengue fever (DF) is a vector-borne disease and a tremendous socioeconomic burden on tropical and subtropical countries worldwide. To explore the characteristics of DF epidemic in the Fujian province, information of DF cases in Fujian during 2004-2014 was collected and analyzed. The complete E genes of 48 viral isolates were amplified and sequenced for phylogenetic analysis. A total of 733 cases was reported, of which 612 (83.5\%) occurred during the peak period from August to October. Additionally, 76\% (190/250) of imported cases originated from Southeast Asia countries, by the epidemiological investigation. Phylogenetic analysis of the 48 viral isolates revealed that three genotypes (I, IV, V) of DENV1, and one genotype each of DENV2 (cosmopolitan) and DENV3 (I) circulated in Fujian during 2004-2014. Similar to the results of the epidemiological investigations, the source of most of the viral isolates, including imported and indigenous cases, may be Southeast Asia countries; however, importation from adjacent provinces was also observed in recent years. Overall, DF is considered an imported epidemic disease in Fujian. Increasing diversity of the viral source and geographic expansion of the area affected by DF in recent years highlights the necessity for strengthening surveillance of the DF epidemic and developing strategies for DF prevention and control in Fujian.
\end{abstract}

dengue virus, $\mathrm{E}$ gene, phylogenetic tree, epidemiology, etiology

Citation: $\quad$ Wang, J., Chen, H., Huang, M., Zhang, Y., Xie, J., Yan, Y., Zheng, K., and Weng, Y. (2017). Epidemiological and etiological investigation of dengue fever in the Fujian province of China during 2004-2014. Sci China Life Sci 60, 72-80. doi: 10.1007/s11427-016-0021-y

\section{INTRODUCTION}

Dengue virus (DENV) is mosquito-borne and is circulated near tropical or subtropical regions between 25 degrees latitudes in the north and south worldwide. There are four serotypes of naturally occurring DENV: DENV1-4 (Russell and Nisalak, 1967). Infection with DENV can cause acute dengue fever (DF), dengue hemorrhagic fever and dengue shock syndrome (Gubler, 1998; Martina et al., 2009). Recently, because of the frequent trading between nations and global climate change, the epidemic regions for DF have

*Corresponding author (email: wengywfjcdc@aliyun.com) expanded and seriously impacted the health of approximately 3.9 billion people living in 128 countries worldwide (Brady et al., 2012). In recent decades, the incidence of DF has increased significantly, with an annual average of 390 million reported cases and nearly 96 million people with apparent clinical manifestations (Bhatt et al., 2013). The prevalence regions include African, American, eastern Mediterranean, Southeast Asia, and west Pacific regions, making DF a global public health issue.

Similar to the worldwide prevalence, regions affected by DENV have continually expanded in China in recent decades, since the first DF outbreak reported in the Guangdong province. However, most infections are clustered in coastal 
provinces in southeast China, such as Guangdong, Guangxi, Fujian, Yunnan, and Hainan (Liu et al., 2014; Jiang et al., 2013). In the Fujian province, imported cases have been reported every year since 2004, and several local clustered epidemics occured in 2004, 2007, 2008, and 2014 (Yan et al., 2006; Chen et al., 2015a, b). To better understand the epidemiological features of DF and provide guidance for disease prevention and control, we comprehensively investigated the epidemiology and etiology of DF in the Fujian province during 2004-2014.

\section{RESULTS}

\section{Epidemiological feature}

Including DF cases imported every year and those cases without dengue hemorrhagic fever, dengue shock syndrome, or death, a total of 733 cases of DF were reported in Fujian province in 2004-2014. Among these, there were 483 local and 250 imported cases. The sex ratio (male/female) of imported cases $(1: 0.64,98 / 152)$ was higher than that of local cases $(1: 1.42,200 / 283)$. However, the median age of imported cases (34 years old; IQR: 35-42 years old) was lower than that of local cases (41 year; IQR: $21-55$ years). A total of $99.4 \%$ of local cases (480/483, Table 1) were identified in Putian, Nanping, and Fuzhou. Such cases mainly occurred in outbreaks in 2004, 2007, 2008, and 2014. A total of $84.4 \%$ of imported cases $(211 / 250)$ were identified in Quanzhou, Fuzhou, Putian, and Xiamen, which included the coastal regions of the Fujian province. It seems that male resident in coastal regions responded mainly to the importation of DF in Fujian. 76\% (190/250) of imported cases were from Southeast Asia countries, including the Philippines, Indonesia, Malaysia, Singapore, Vietnam, Cambodia, Myanmar, Thailand, and East Timor. Ten cases were imported from India, Bangladesh, Sri Lanka, and Saudi Arabian in south Asia, 11 cases from Angola and Ghana in Africa, 12 from Papau New Guinea in Oceanic continents, and 3 from Suriname and Brazil in South America. In addition, 24 cases were imported from the provinces of Guangdong, Yunnan, and Hainan in mainland China through inter-regional transmission (Table 2). The monthely distribution revealed that DF cases occurred in each month and the incidence peaked from August to October, with $83.5 \%$ of cases $(612 / 733)$ reported during the period (Figure 1).

Table 1 Summary of reported DF cases in Fujian in 2004-2014

\begin{tabular}{|c|c|c|c|c|c|c|c|c|c|c|c|c|}
\hline Type of case & 2004 & 2005 & 2006 & 2007 & 2008 & 2009 & 2010 & 2011 & 2012 & 2013 & 2014 & Total \\
\hline Local cases & 93 & 0 & 0 & 103 & 9 & 0 & 1 & 0 & 0 & 1 & 276 & 483 \\
\hline Imported cases & 9 & 14 & 3 & 9 & 16 & 14 & 23 & 18 & 26 & 61 & 57 & 250 \\
\hline Total cases & 102 & 14 & 3 & 112 & 25 & 14 & 24 & 18 & 26 & 62 & 333 & 733 \\
\hline
\end{tabular}

Table 2 Origin of imported DF cases found in Fujian in 2004-2014

\begin{tabular}{|c|c|c|c|c|c|c|c|c|c|c|c|c|}
\hline Year & 2004 & 2005 & 2006 & 2007 & 2008 & 2009 & 2010 & 2011 & 2012 & 2013 & 2014 & Total \\
\hline Philippines & 8 & 2 & 1 & 6 & 4 & 1 & 12 & 11 & 15 & 8 & 7 & 75 \\
\hline Indonesia & 1 & 1 & 1 & - & 5 & 9 & 3 & 1 & 1 & 13 & 9 & 44 \\
\hline Malaysia & - & 2 & - & 2 & 4 & 1 & 4 & - & 3 & 4 & 5 & 25 \\
\hline Singapore & - & 9 & - & 1 & 2 & 2 & - & 2 & 1 & 5 & 2 & 24 \\
\hline Viet nam & - & - & 1 & - & - & - & 2 & - & 1 & - & 2 & 6 \\
\hline Cambodia & - & - & - & - & 1 & - & - & 2 & 1 & 1 & - & 5 \\
\hline Myanmar & - & - & - & - & - & - & - & 1 & - & 1 & - & 2 \\
\hline Thailand & - & - & - & - & - & - & - & - & 1 & 3 & 3 & 7 \\
\hline East Timor & - & - & - & - & - & - & - & - & - & 1 & 1 & 2 \\
\hline Bangladesh & - & - & - & - & - & - & - & 1 & - & - & - & 1 \\
\hline Sri Lanka & - & - & - & - & - & - & - & - & - & 1 & - & 1 \\
\hline India & - & - & - & - & - & - & - & - & - & 7 & - & 7 \\
\hline Angola & - & - & - & - & - & - & - & - & - & 9 & 1 & 10 \\
\hline Ghana & - & - & - & - & - & - & - & - & - & - & 1 & 1 \\
\hline Suriname & - & - & - & - & - & 1 & - & - & 1 & - & - & 2 \\
\hline Brazil & - & - & - & - & - & - & 1 & - & - & - & - & 1 \\
\hline Papua New Guinea & - & - & - & - & - & - & 1 & - & 2 & 6 & 3 & 12 \\
\hline Yunnan & - & - & - & - & - & - & - & - & - & 1 & - & 1 \\
\hline Guangdong & - & - & - & - & - & - & - & - & - & - & 22 & 22 \\
\hline Hainan & - & - & - & - & - & - & - & - & - & - & 1 & 1 \\
\hline
\end{tabular}




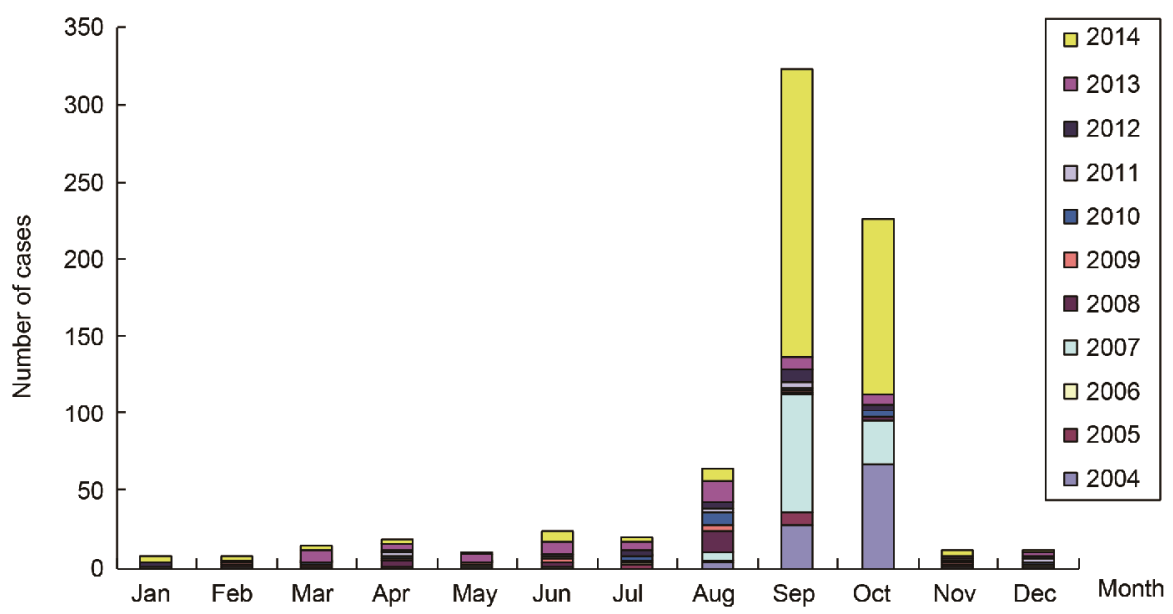

Figure 1 Monthly distribution of reported DF cases in Fujian between 2004 and 2014.

\section{Etiological analysis}

Forty-eight strains of DENV, including 29 DENV1, 16 DENV2, and 3 DENV3, were isolated from DF patients in Fujian province in 2004-2014 (Table 3). Of these viruses, 21 strains were isolated from imported cases. For sequence designation, the viral isolates were named "Type/Province/ Serial number/Year." whereas the reference sequences (downloaded from Genbank) were expressed as "Accession no./Origin/Year." Complete E sequences of 48 of the above strains were obtained and aligned with reference DENV sequences, followed by construction of a phylogenetic tree. The detailed phylogenetic analysis of DENV of various serotypes described below.

\section{DENV1}

The phylogenetic tree (Figure 2) revealed that the DENV1 isolates belonged to genotype I, IV and $\mathrm{V}$, respectively. Consistent with the results of field epidemiological investigation, the viral isolates from imported cases were genetically similar to the viruses circulating in regions to which the cases traveled. Six sporadic isolates imported from aboard were thought have originated from countries in Southeast Asia, whereas three isolates of D1/FJ/011/2013, D1/FJ/023/2013, and D1/FJ/031/2013 from Angola in Africa In addition, two isolates (D1/FJ/346/2014 and D1/FJ/ $353 / 2014$ ) of genotype I were imported from the adjacent Guangdong province. However, phylogenetic analysis indicated that strain D1/FJ/003/2012 originated from Southeast Asia and was distinct from current South American strains (Zhang et al, 2013). Given the high sequence identity (more than 99.3\%) with the virus found in Indonesia (JF967877/ Indonesia/2009), the viral source of the local DF outbreak in 2004 (genotype I) was thought to be countries in Southeast Asia, including Indonesia. DENV1 has continually circulated in Guangdong province for at least 18 years since 1997 (Shen et al., 2015). Phylogenetic analysis revealed that DENV1 caused a large outbreak in Guangdong in 2014 and included genotypes I, IV, and V (Sun et al., 2016). Even for identical genotypes, multiple sub-lineages, which may have developed from continued evolution of the virus (Holmes and Burch, 2000) rather than from importations, cocirculated in DENV1 in the province. Therefore, except for the possible source of viruses leading to the outbreak in Nanping city originating from Singapore (for $99.8 \%$ identity with the virus KJ806966/Singapore/2013), another possible origin from Guangdong should be considered. The importation of viruses (D1/FJ/335/2014 and D1/FJ/466/2014), similarly to KP723473/Guangdong/2014 of genotype V, was determined through calculations. Furthermore, retrospective seroepidemiological investigations demonstrated that the early cases with seropositive tests, had traveled to Guangdong province.

\section{DENV2}

Of the 16 DENV2 strains obtained in this study, 13 were from patients in local outbreaks that occurred in 2007, 2008, and 2014. Three were from familial clustered cases that had a travel history to Indonesia in 2013, prior to illness onset. The phylogenetic tree (Figure 3) of DENV2 revealed only genotype cosmopolitan found in Fujian in 2004-2014. For three viruses (D2/FJ/161/2013, D2/FJ/162/2013, D2/FJ/ 163/2013) from familial clustered cases, the virus available in the public sequence database showing the highest genetic identity (99.7\%) was KJ806901/Malaysia/2013, which is inconsistent with the results of field investigation. A similar virus may have circulated in Indonesia during same period, accounting for the familial infection. DENV2 of genotype cosmopolitan was reported to circulate in Guangdong in 2014 (Sun et al., 2016; Zhao et al., 2014), while the most similar virus to Nanping isolates (D2/FJ/269/2014 and D2/FJ/270/2014) was KP06452/Guangdong/2014; therefore, these two isolates may have originated from the adjacent Guangdong province. Eleven viruses with high sequence identity from three outbreaks events in Putian in 2007,2008 , and 2014 originated in Southeast 
Table 3 Summary of DENV isolates in Fujian in 2004-2014 $4^{\text {a) }}$

\begin{tabular}{|c|c|c|c|c|c|c|c|}
\hline Isolate & Location & Date of onset & Origin ${ }^{*}$ & Isolate & Location & Date of onset & Origin $^{*}$ \\
\hline D1/FJ/397/2004 & Fuzhou & 2004.10 .3 & Local & D1/FJ/341/2014 & Nanping & 2014.9.18 & Local \\
\hline $\mathrm{D} 1 / \mathrm{FJ} / 412 / 2004$ & Fuzhou & 2004.10 .6 & Local & D1/FJ/346/2014 & Fuzhou & 2014.10 .13 & Guangdong \\
\hline $\mathrm{D} 1 / \mathrm{FJ} / 431 / 2004$ & Fuzhou & 2004.10 .8 & Local & D1/FJ/353/2014 & Ningde & 2014.10 .13 & Guangdong \\
\hline $\mathrm{D} 1 / \mathrm{FJ} / 064 / 2010$ & Fuzhou & 2010.7 .31 & Vietnam & D1/FJ/463/2014 & Fuzhou & 2014.6 .27 & Indonesia \\
\hline D1/FJ/003/2012 & Fuzhou & 2012.1 .3 & Suriname & $\mathrm{D} 1 / \mathrm{FJ} / 466 / 2014$ & Fuzhou & 2014.10 .3 & Guangdong \\
\hline D1/FJ/189/2012 & Fuzhou & 2012.10 .14 & Vietnam & D2/FJ/091/2007 & Putian & 2007.9.19 & Local \\
\hline D1/FJ/023/2013 & Fuzhou & 2013.3 .28 & Angola & $\mathrm{D} 2 / \mathrm{FJ} / 368 / 2007$ & Putian & 2007.10 .1 & Local \\
\hline D1/FJ/031/2013 & Xiamen & 2013.4 .4 & Angola & D2/FJ/373/2007 & Putian & 2007.9 .28 & Local \\
\hline $\mathrm{D} 1 / \mathrm{FJ} / 072 / 2013$ & Fuzhou & 2013.6.2 & Singapore & D2/FJ/399/2007 & Putian & 2007.10 .1 & Local \\
\hline D1/FJ/189/2013 & Putian & 2013.8 .12 & Thailand & $\mathrm{D} 2 / \mathrm{FJ} / 102 / 2008$ & Putian & 2008.8 .23 & Local \\
\hline $\mathrm{D} 1 / \mathrm{FJ} / 202 / 2013$ & Fuzhou & 2013.8.19 & Philippine & $\mathrm{D} 2 / \mathrm{FJ} / 161 / 2013$ & Fuzhou & 2013.8 .13 & Indonesia \\
\hline $\mathrm{D} 1 / \mathrm{FJ} / 006 / 2014$ & Longyan & 2014.1.9 & Vietnam & D2/FJ/162/2013 & Fuzhou & 2013.8 .13 & Indonesia \\
\hline $\mathrm{D} 1 / \mathrm{FJ} / 210 / 2014$ & Nanping & 2014.9.18 & Local & $\mathrm{D} 2 / \mathrm{FJ} / 163 / 2013$ & Fuzhou & 2013.8 .13 & Indonesia \\
\hline $\mathrm{D} 1 / \mathrm{FJ} / 212 / 2014$ & Nanping & 2014.9.18 & Local & $\mathrm{D} 2 / \mathrm{FJ} / 232 / 2014$ & Putian & 2014.9 .17 & Local \\
\hline $\mathrm{D} 1 / \mathrm{FJ} / 213 / 2014$ & Nanping & 2014.9.17 & Local & D2/FJ/236/2014 & Putian & 2014.9.18 & Local \\
\hline $\mathrm{D} 1 / \mathrm{FJ} / 214 / 2014$ & Nanping & 2014.9 .15 & Local & $\mathrm{D} 2 / \mathrm{FJ} / 239 / 2014$ & Putian & 2014.9.19 & Local \\
\hline $\mathrm{D} 1 / \mathrm{FJ} / 216 / 2014$ & Nanping & 2014.9.18 & Local & $\mathrm{D} 2 / \mathrm{FJ} / 242 / 2014$ & Putian & 2014.9.13 & Local \\
\hline $\mathrm{D} 1 / \mathrm{FJ} / 217 / 2014$ & Nanping & 2014.9.14 & Local & $\mathrm{D} 2 / \mathrm{FJ} / 269 / 2014$ & Nanping & 2014.9.22 & Local \\
\hline $\mathrm{D} 1 / \mathrm{FJ} / 220 / 2014$ & Nanping & 2014.9.17 & Local & $\mathrm{D} 2 / \mathrm{FJ} / 270 / 2014$ & Nanping & 2014.9 .22 & Local \\
\hline D1/FJ/222/2014 & Nanping & 2014.9.17 & Local & D3/FJ/022/2007 & Fuzhou & 2007.6.11 & Indonesia \\
\hline $\mathrm{D} 1 / \mathrm{FJ} / 224 / 2014$ & Nanping & 2014.9.19 & Local & D3/FJ/079/2010 & Quanzhou & 2010.8 .14 & Philippine \\
\hline $\mathrm{D} 1 / \mathrm{FJ} / 335 / 2014$ & Fuzhou & 2014.10 .10 & Guangdong & D3/FJ/077/2010 & Quanzhou & 2010.8 .16 & Philippine \\
\hline
\end{tabular}

a) * indicates that origin was deduced according to the case investigation.

Asia. Despite the high similarity between isolates from Putian in the 2014 outbreak and sporadic isolate from Guangdong (KJ807796/Guangdong/2013), the chronological relationship did not support the viral spread from Guangdong to Fujian. Despite the simultaneous occurrence of DENV2 in Putian and Nanping in 2014, the genetic heterogeneity between the viruses did not support inter-region transmission across these two cities.

\section{DENV3}

Only three viral strains were isolated from sporadic imported patients in 2004-2014, one from Indonesia and 2 from the Philippines. The phylogenetic tree (Figure 4) also showed that all DENV3 isolates belonged to genotype I. Based on phylogenetic analysis and field epidemiological investigation, the three viruses originated from countries in Southeast Asia. Historically, DF outbreaks associated with DENV3 occurred in Guangdong and Hainan during the 1970 and 1980s (Zhao et al., 1981; Li et al., 1986). Reported cases of DENV3 infection during the subsequent 20 years were relatively rare compared to DENV1 and DENV2 in mainland China (Wu et al., 2010). However, in recent years, the frequent importation of DENV3 of various genotypes initiated DF outbreaks in Yiwu city in Zhejiang (Genotype III, 2009) (Sun et al., 2011), Xishuangbanna autonomous prefecture in Yunnan (genotype II, 2013) (Guo et al., 2015), and even in the central regions in China, such as the
Henan province (genotype II, 2013) (Huang et al., 2014). Frequent outbreaks and geographic expansion of DENV3 increased the potential for inter-regions transmission of the virus. Indeed, we identified a DF case imported from Yunnan province in 2013 (Table 3) during field investigation. However, the phylogenetic tree failed to reveal the relationship between the viruses in Fujian and Yunnan by viral isolation and sequencing.

\section{DISCUSSION}

DENV is an enveloped, single positive-strand RNA virus belonging to the Flavivius genus of Flaviviridae. DENV can be classified into four serotypes, each of which includes several genotypes (Holmes and Burch, 2000; Holmes, 2009). Similar to other RNA viruses, mutations frequently occur during the viral replication process in DENV because viral RNA polymerase lacks a proofreading mechanism, and resulting in endemic disease. In recent years, etiological analysis methods have been developed to examine viral phylogeny; the gene encoding the major outer membrane protein of the virus, which plays important roles in interactions between the virus and host cell has attracted the most attention (Parameswaran et al., 2012; Lemmon and Milinkovitch, 2002; Rico-Hesse, 2003).

In this study, we investigated the epidemiology and etiology of the DF epidemic in Fujian during 2004-2014. The 


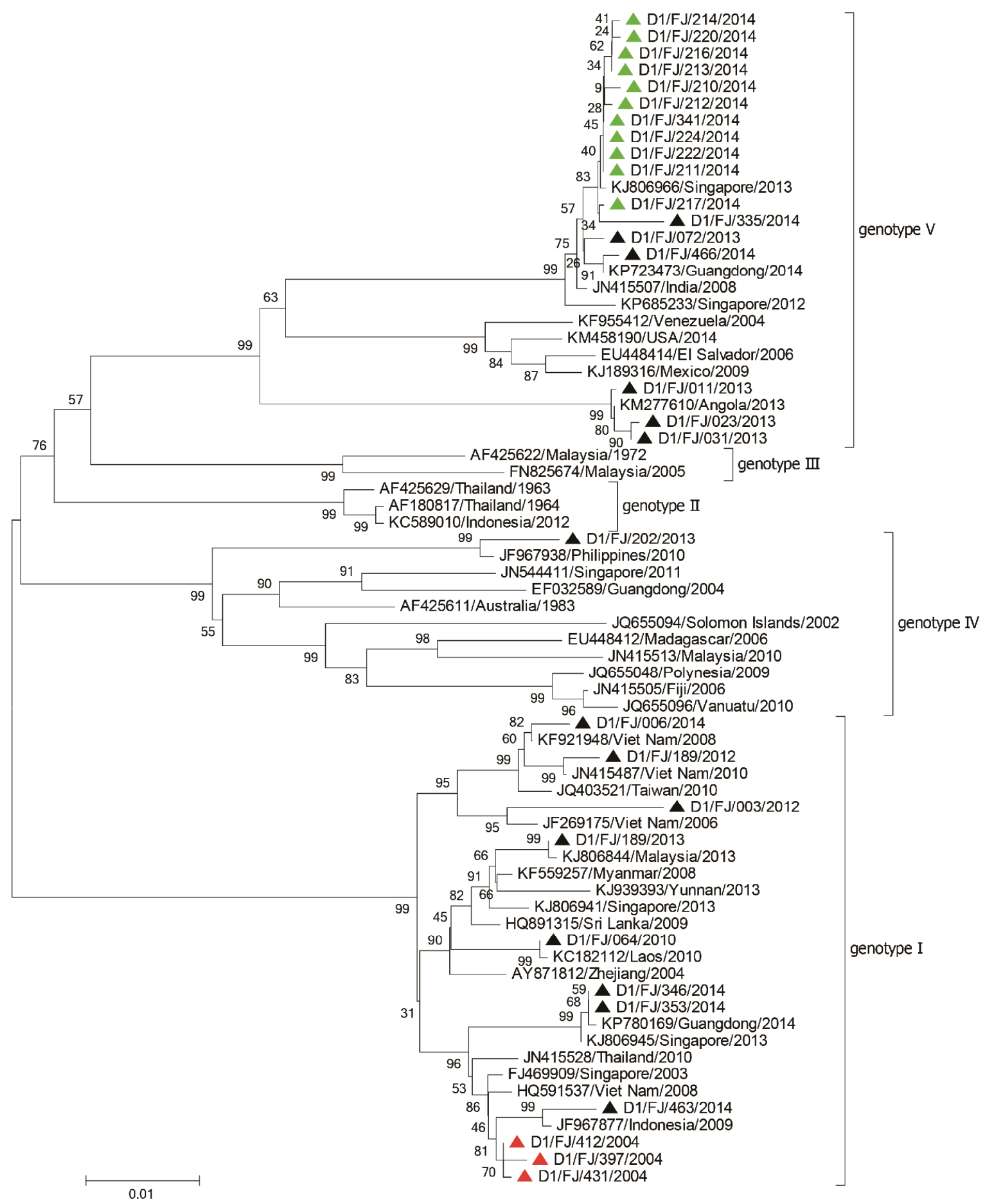

Figure 2 Phylogenetic tree of DENV-1 E gene isolated in Fujian between 2004 and 2014. Solid triangle symbol in red and green indicate strains isolated from the outbreaks in 2004 and 2014, respectively, and that in black indicates the strains from sporadic cases with DENV-1 infection.

results showed that the epidemic peak of DF in Fujian occurred from August to October. The origin of most imported DF cases was tracked to countries in Southeast Asia; however, cases from countries in Africa, Oceania, and South America were also reported in recent years. Importantly, the viral source of some local cases, whether sporadic or outbreaks, was found in recent years (2013-2014) in Fujian, and were either confirmed or suspected to have originated from adjacent provinces, particularly from Guangdong, according to epidemiological investigations and phylogenetic analysis. This phenomenon highlights the probable geographic expansion of the DF epidemic in future through inter-region transmission of DF in mainland China. Furthermore, inter-region transmission may not only increase 


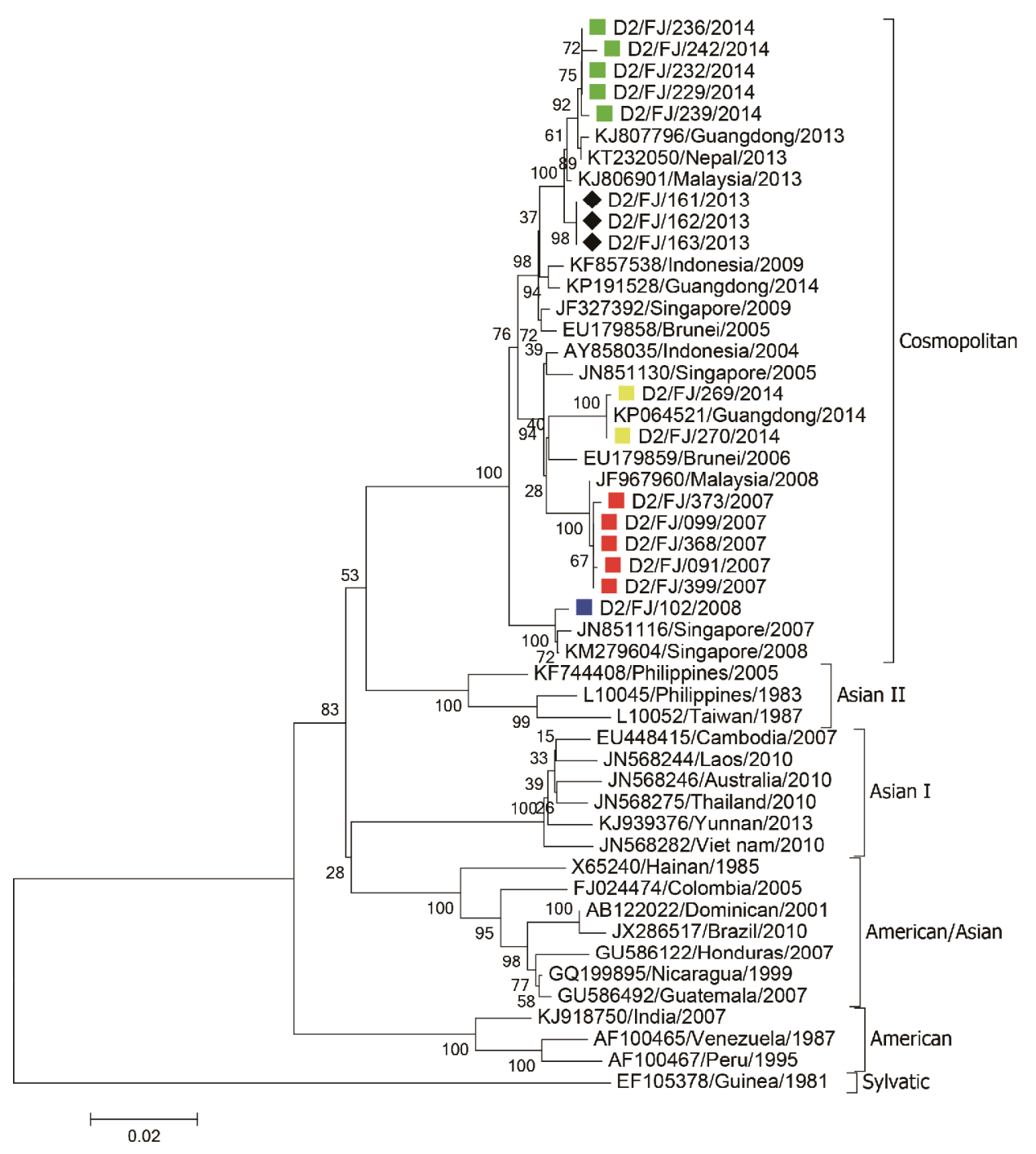

Figure 3 Phylogenetic tree of DENV-2 E gene isolated in Fujian between 2004 and 2014. Solid square symbol in red, blue, green, and yellow indicate the strains isolated from the outbreaks in 2007, 2008, and 2014 in Putian and 2014 in Nanping, respectively. The three clustered imported cases from Southeast Asia are marked with a black diamond.

the incidence in traditional DF-affected areas, but also introduce viral agents into unaffected areas. For example, most DF cases were distributed only in coastal regions in the past in Fujian; however, the outbreak of DF in inland Nanping city in 2014 may have been initiated by a domestic imported case. Increasing diversity of the viral source and geographic expansion highlights the risk of DF outbreaks in Fujian, and throughout the country (Wu et al., 2010).

Phylogenetic analysis is useful for tracking viral sources and understanding the relationships between various outbreak events. Combined with field epidemiological investigations, the results revealed not only the possible source of DENVs causing indigenous outbreaks in Fujian province, but also etiological relationships between various outbreak events. For instance, the viral agents of DENV causing sequential outbreaks in Putian in 2007, 2008, and 2014 were phylogenetically different and unrelated to the DF endemic in the region. In addition, similar results were observed for simultaneous DF outbreaks in Putian and Nanping in 2014, which also excluded the possibility of inter-region transmission in Fujian.

Fujian province is located in the southeast coastal region of China and is one of the provinces most affected by DENV in China. As a well-known hometown of overseas Chinese individuals, Fujian is closely related to Southeast Asia, one of the epicenters of DF worldwide, resulting in frequent importation of DF. In recent years, increasing global trade activities, continual labor exportation, and frequent migration of populations between rural regions and coastal developed cities have facilitated the import of viral agents of DENV, not only from aboard but also from adjacent provinces. DF is characterized as an imported epidemic disease in Fujian, without any evidence support the endemic. However, in addition to the frequent importation of viral 


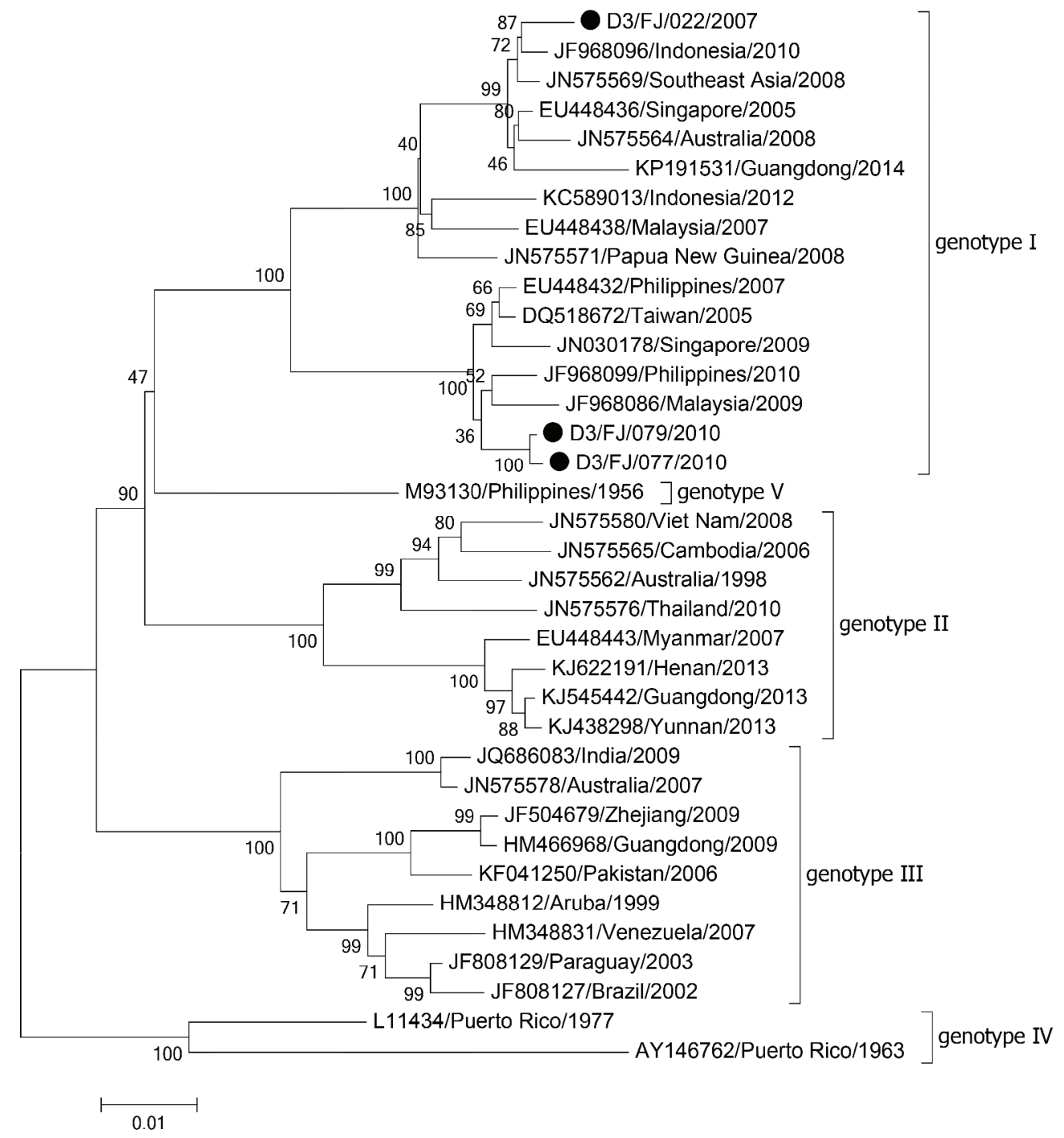

Figure 4 Phylogenetic tree of DENV-3 E gene isolated in Fujian between 2004 and 2014. The viral strains isolated in Fujian are marked with a black solid circle.

agents, risk factors such as the expansive distribution of Aedes albopictus (Fang et al., 2013; Xie et al., 2013), suitable climate conditions for mosquito vector breeding, and uncontrolled urbanization contribute to the expansion of DF epidemics. These factors promote the potential for transformation of an imported epidemic to endemic (Shen et al., 2015; Chen and Han, 2016). In the past, strategies for controlling DF have focused more on coastal regions in Fujian; however, the diversity of the viral source and geographical expansion of DF suggested that it was necessary to strengthen epidemiological and etiological surveillance, not only in coastal regions but also in inland regions. In additions, because case recognition and management in the early stage of an epidemic is crucial for DF control, strengthening professional training targeting clinical personnel at various levels of medical units must be considered when developing strategies for DF control and prevention.

\section{MATERIALS AND METHODS}

\section{Materials}

\section{Epidemiological data}

Basic epidemiological data of patients confirmed to have DENV infection were collected from the China Information System for Disease Control and Prevention, including the information management system for infectious disease report and emerging public health events report. Detailed case information was collected and sorted from interview questionnaires collected in field epidemic investigations.

\section{Case definition}

The definition of the imported cases adopted in field epidemiological investigation was that the individual case had a travel history to DF-epidemic foreign countries or other provinces in China and exposure to mosquito biting within 
15 days (the longest incubation of disease) prior to illness onset. The regions that the cases returned to or came from were regarded as the localities of viral infection (Guideline of national dengue surveillance in China. http://www.moh. gov.cn/uploadfile/2005818141858129.doc).

\section{Viral isolation}

The mosquito C6/36 cell was used to isolate DENV virus from serum specimens collected from sporadic or clusters DF patients in Fujian province in 2004-2014. The isolates were confirmed by indirect immunofluorescent assay and specific reverse transcription PCR (Lanciotti et al., 1992) and viral stocks were frozen at $-80^{\circ} \mathrm{C}$.

\section{Reagents}

The reagents for viral RNA extraction, one-step reverse transcription PCR (RT-PCR), amplicon purification by gel extraction, and mini plasmid preparation were purchased from Qiagen (Hilden, Germany). The TA cloning kit and Escherichia coli DH5 $\alpha$ competent cells were purchased from TaKaRa (Shiga, Japan). Other reagents were prepared using standard procedures. Specific primers (Table 4) for amplification of the viral complete envelope (E) gene were described previously (Huang et al., 2012).

\section{Methods}

\section{RNA extraction}

First $140 \mu \mathrm{L}$ of the viral stock was used for viral RNA extraction with the QIAamp Viral RNA Mini Kit, according to the manufacturer's instructions. RNA were eluted in $50 \mu \mathrm{L}$ diethyl pyrocarbonate treated $\mathrm{H}_{2} \mathrm{O}$ and frozen at $-20^{\circ} \mathrm{C}$ until use.

\section{Amplification of full length E gene}

The PCR mixture included the following: $5 \mu \mathrm{L} 5 \times$ buffer, $1 \mu \mathrm{L}$ dNTPs (2.5 mmol L ${ }^{-1}$ each), $1 \mu \mathrm{L}$ enzyme mix, $1.5 \mu \mathrm{L}$ sense primer and $1.5 \mu \mathrm{L}$ antisense primer $\left(10 \mu \mathrm{mol} \mathrm{L}^{-1}\right)$, $10 \mu \mathrm{L}$ diethyl pyrocarbonate treated $\mathrm{H}_{2} \mathrm{O}$, and $5 \mu \mathrm{L}$ RNA template. The final $25 \mu \mathrm{L}$ reaction mixture was incubated at $50^{\circ} \mathrm{C}$ for $30 \mathrm{~min} ; 94^{\circ} \mathrm{C}$ for $15 \mathrm{~min} ; 30$ cycles of $94^{\circ} \mathrm{C}$ for $30 \mathrm{~s}, 45^{\circ} \mathrm{C}$ for $30 \mathrm{~s}, 72^{\circ} \mathrm{C}$ for $30 \mathrm{~s} ; 72^{\circ} \mathrm{C}$ for $5 \mathrm{~min}$, and maintained at $4^{\circ} \mathrm{C}$. Next, $40 \mu \mathrm{L}$ of amplified products were separated by $1 \%$ agarose gel electrophoresis at $110 \mathrm{~V}$ for $40 \mathrm{~min}$, and the target cDNA was purified using a gel

Table 4 Primers used to amplify E gene by RT-PCR

\begin{tabular}{llll}
\hline Serotype & Sequence $\left(5^{\prime} \rightarrow 3^{\prime}\right)$ & $\begin{array}{l}\text { Orienta- } \\
\text { tion }\end{array}$ & Length \\
\hline DENV 1 & $\begin{array}{l}\text { ATAGGAACATCCATCAC } \\
\text { TGCCRCTTCCACATTTGAG }\end{array}$ & $\begin{array}{l}\text { sense } \\
\text { antisense }\end{array}$ & $1,609 \mathrm{bp}$ \\
\hline \multirow{2}{*}{ DENV 2 } & $\begin{array}{l}\text { TTGAGACATCCAGGCTTCACC } \\
\text { CCACTATCGGCCTGCACCAT }\end{array}$ & $\begin{array}{l}\text { sense } \\
\text { antisense }\end{array}$ & $1,610 \mathrm{bp}$ \\
\hline \multirow{2}{*}{ DENV 3 } & CCATCCATGACAATGAGATG & sense & \multirow{2}{*}{$\begin{array}{l}\text { s.591 bp } \\
\end{array}$} \\
\end{tabular}

extraction kit according to the manufacturer's protocol.

\section{Plasmid preparation}

Purified DNA fragments were cloned into the pMD ${ }^{\circledR} 19-\mathrm{T}$ vector according to the manufacturer's instructions. Recombinant plasmids were transformed into E. coli $\mathrm{DH} 5 \alpha$ competent cells and cultured on Luria-Bertani plates (containing $100 \mu \mathrm{g} \mathrm{mL}^{-1}$ ampicillin, $0.5 \mathrm{mmol} \mathrm{L}^{-1}$ Isopropyl $\beta$-D-Thiogalactoside (IPTG), and $40 \mu \mathrm{g} \mathrm{mL}^{-1} \mathrm{X}$-gal). Bacterial colonies were picked using the blue-white screening method from LB plates, followed by cultured in liquid LB media at $37^{\circ} \mathrm{C}$ overnight. The recombinant plasmids were prepared using the TIANprep Mini plasmid kit (Tiangen Biotech, Beijing) followed by bidirected circular sequencing reactions using the Bigdye 3.1 kit (Applied Biosystems, USA). The plasmids were sequenced by TaKaRa Inc. using the sequencing primers M13-47 and RV-M, which flanked the insert position. The sequences obtained in this study were deposited in GenBank (accession No. KU570088KU570133).

\section{Phylogenetic reconstruction}

Complete E gene sequences were assembled using the SeqMan program (Lasergene software package, DNASTAR Inc., USA) and aligned using Mega software 6.0, with the sequences of reference DENV strains download from Genbank. Phylogenetic trees of the viral E genes were constructed using the neighbor-joining method.

Compliance and ethics The author(s) declare that they have no conflict of interest.

Acknowledgements This study was supported by Chinese National $H i$-Tech research development plan (2011AA02A114), Chinese National Major Science \& technology project (2012ZA10004-210), and Fujian provincial medical innovation project (2015-CXB-13).

Brady, O.J., Gething, P.W., Bhatt, S., Messina, J.P., Brownstein, J.S., Hoen, A.G., Moyes, C.L., Farlow, A.W., Scott, T.W., and Hay, S.I. (2012). Refining the global spatial limits of dengue virus transmission by evidence-based consensus. PLoS Negl Trop Dis 6, e1760.

Bhatt, S., Gething, P.W., Brady, O.J., Messina, J.P., Farlow, A.W., Moyes, C.L., Drake, J.M., Brownstein, J.S., Hoen, A.G., Sankoh, O., Myers, M.F., George, D.B., Jaenisch, T., Wint, G.R., Simmons, C.P., Scott, T.W., Farrar, J.J., and Hay, S.I. (2013). The global distribution and burden of dengue. Nature 496, 504-507.

Chen, R. and Han, G. (2016). Dengue in China: comprehensive phylogenetic evaluation reveals evidence of endemicity and complex genetic diversity. Am J Trop Med Hyg 94, 198-202.

Chen, W., Wu, S., and Hong, R. (2015a). Prevalent characteristics dengue fever in Fujian province, 2004-2013 (in Chinese). Chin J Public Health, $31,1-4$.

Chen, W., Wang, J., Zhang, Y., Chen, H., Wu, S., Weng, Y., Zheng, K., and Yan, Y. (2015b). Epidemiological characterization of dengue cases in Fujian Province, 2009-2014 (in Chinese). Chin J Zoonoses 31, 589-591.

Fang, Y., Gao, B., Wang, Y., Xiao, W., Xu, B., Zhang, J., Wang, G., and $\mathrm{Wu}, \mathrm{R}$. (2013). Investigation on mosquito-borne species and breeding environment at ports to Taiwan in Fujian (in Chinese). Chin J Front 
Health Quarant 36, 92-95.

Gubler, D.J. (1998). Dengue and dengue hemorrhagic fever. Clin Microbiol Rev, 1998, 480-496.

Guo, X., Yang, H., Wu, C., Jiang, J., Fan, J., Li, H., Zhu, J., Yang, Z., Li, Y., Zhou, H., and Zhang, J. (2015). Molecular characterization and viral origin of the first dengue outbreak in Xishuangbanna, Yunnan Province, China, 2013. Am J Trop Med Hyg 93, 390-393.

Holmes, E.C. and Burch, S.S. (2000). The causes and consequences of genetic variation in dengue virus. Trends Microbiol, 8, 74-77.

Holmes, E.C. (2009). RNA virus genomics: a world of possibilities. J Clin Invest, 119, 2488-2495.

Huang, M., Zhang, Y., Lin, M., Wang, J., Yan, Y., and Weng, Y., (2012). Sequence analysis of envelope genes in dengue viruses from Fujian Province, 2004-2010. Chin J Zoonoses 28, 973-977.

Huang, X., Ma, H., Wang, H., Du, Y., Su, J., Li, X., Tang, X., Ma, H., Zu, B., Zhang, Q., Chen, H., and Xu B. (2014). Outbreak of dengue fever in central China, 2013. Biomed Environ Sci 27, 894-897.

Jiang, L., Wu, X., Wu, Y., Bai, Z., Jing, Q., Luo, L., Dong, Z., Yang, Z., Xu, Y., Cao, Y., Di, B., Wang, Y., and Wang, M. (2013). Molecular epidemiological and virological study of dengue virus infections in Guangzhou, China, during 2001-2010. Virol J 10, 4.

Lai, S., Huang, Z., Zhou, H., Anders, K.L., Perkins, T.A., Yin, W., Li, Y., Mu, D., Chen, Q., Zhang, Z., Qiu, Y., Wang, L., Zhang, H., Zeng, L., Ren, X., Geng, M., Li, Z., Tatem, A.J., Hay, S.I., and Yu, H. (2015). The changing epidemiology of dengue in China, 1990-2014: a descriptive analysis of 25 years of nationwide surveillance data. BMC Med, 13,100 .

Lanciotti, R.S., Calisher, C.H., Gubler, D.J., Chang, G.J., and Vorndam, A.V. (1992). Rapid detection and typing of Dengue viruses from clinical samples by using reverse transcriptase-polymerase chain reaction. J Clin Microbiol, 30, 545-551.

Lemmon, A.R., and Milinkovitch, M.C. (2002). The metapopulation genetic algorithm: an efficient solution for the problem of large phylogeny estimation. Proc Natl Acad Sci USA 99, 10516-10521.

Li, F., Yang, F., Song, J., Gao, H., Tang, J., Zou, C., Hu, B., Wen, S., and Qiu, F. (1986). Etiologic and serologic investigations of the 1980 epidemic of dengue fever on Hainan Island. China Am J Trop Med Hyg $35,1051-1054$

Liu, C., Liu, Q., Lin, H., Xin, B., and Nie, J. (2014). Spatial analysis of dengue fever in Guangdong Province, China, 2001-2006. Asia Pac J Public Health, 26, 58-66.
Martina, B.E., Koraka, P., Osterhaus, A.D. (2009). Dengue virus pathogenesis: an integrated view. Clin Microbiol 22, 564-581.

Parameswaran, P., Charlebois, P., Tellez, Y., Nunez, A., Ryan, E.M., Malboeuf, C.M., Levin, J.Z., Lennon, N.J., Balmaseda, A., Harris, E., and Henn, M.R. (2012). Genome-wide patterns of intrahuman dengue virus diversity reveal associations with viral phylogenetic clade and interhost diversity. J Virol 86, 8546-8558.

Rico-Hesse, R. (2003). Microevolution and virulence of dengue viruses. Adv Virus Res 59, 315-341.

Russell, P.K., and Nisalak, A. (1967). Dengue virus identification by the plaque reduction neutralization test. J Immunol 99, 291-296.

Shen, S., Wei, H., Fu, Y., Zhang, H., Mo, Q., Wang, X., Deng, S., Zhao, W., Liu, Y., Feng, X., Chen, W., and Peng, H. (2015). Multiple sources of infection and potential endemic characteristics of the large outbreak of dengue in Guangdong in 2014. Sci Rep 23, 16913.

Sun, J., Lin, J., Yan, J., Fan, W., Lu, L., Lv, H., Hou, J., Ling, F., Fu, T., Chen, Z., Cong, L., Liu, Q., Zhang, Y., and Chai, C. (2011). Dengue virus serotype 3 subtype III, Zhejiang Province, China. Emerg Infect Dis $17,321-323$.

Sun, J., Wu, D., Zhou, H., Zhang, H., Guan, D., He, X., Cai, S., Ke, C., and Lin, J. (2016). The epidemiological characteristics and genetic diversity of dengue virus during the third largest historical outbreak of dengue in Guangdong, China, in 2014. J Infect 72, 80-90.

Wu, J., Lun, Z.R., James, A.A., and Chen, X. (2010). Review: dengue fever in mainland China. Am J Trop Med Hyg 83, 664-671.

Xie H., Zhang S., Lin Y, Fang, Y., Lin, Y., and Oü, Y. (2013). Investigation on density and ecological characteristics of aedes albopictus in $\mathrm{Fu}-$ jian (in Chinese). J Med Pest Control 29, 123-124.

Yan, Y., Hong, R., Shen, X., Weng, Y., Cai, S., Xu, B., Li, S., He, J., Xu, L., Lin, Y., Zheng, N., Lin, M., and Lin, S. (2006). Study on the epidemiology and etiologic agent of Dengue fever outbreaks in Fuzhou in 2004 (in Chinese). Zhonghua Liu Xing Bing Xue Za Zhi 27, 371-374.

Zhang, Y., Wang, J., Huang M., Wu, S., and Weng, Y. (2013). Genomic characterization of a dengue-1 virus originated from South America. Chin J Zoonoses 29, 665-669.

Zhao, H., Luo, Q., and Shen, G., (1981). Epidemiology of the dengue outbreak in Shiwanzhen, Nanhai County, Guangdong Province (in Chinese). Chin Med J 61, 466-469.

Zhao, H., Zhao, L., Jiang T., Li, X., Fan, H., Hong, W., Zhang, Y., Zhu, Q., Ye, Q., Tong, Y., Cao, W., Zhang, F., and Qin, C. (2014). Isolation and characterization of dengue virus serotype 2 from the large dengue outbreak in Guangdong, China in 2014. Sci China Life Sci 57, 1149-1155.

Open Access This article is distributed under the terms of the Creative Commons Attribution License which permits any use, distribution, and reproduction in any medium, provided the original author(s) and source are credited. 